\title{
Congenital Curved Nail of the Fourth Toe Associated with Oral Disorders
}

\author{
Nilton Di Chiacchio ${ }^{\mathrm{a}}$ Leandro Noriega $^{\mathrm{a}}$ Nilton Gioia Di Chiacchio ${ }^{\mathrm{a}}$ \\ Jorge Ocampo-Garza ${ }^{b}$ Emerson Henrique Padoveze ${ }^{a}$ \\ a Dermatology Clinic, Hospital do Servidor Público Municipal de São Paulo, São Paulo, Brazil; b Dermatology \\ Department, University Hospital “Dr. José Eleuterio González,” Universidad Autónoma de Nuevo León, \\ Monterrey, México
}

\section{Established Facts}

- Congenital curved nail of the fourth toe represents an unusual deformity in which the nail of the fourth toe curves in a plantar direction.

- Distal bone and soft tissue hypoplasia usually occur.

\section{Novel Insights}

- We describe a case of congenital curved nail of the fourth toe associated with bifid uvula.

\section{Keywords}

Bifid uvula . Congenital curved nail of the fourth toe $\cdot$ Nail deformity

\begin{abstract}
Congenital curved nail of the fourth toe represents an unusual deformity in which the nail of the fourth toe curves in a plantar direction. It is unknown why only this toe is affected; however, the initial descriptions suggest that this is a mesodermal defect. We describe a case of congenital curved nail of the fourth toe associated with bifid uvula. There are only 2 reports mentioning the association of this nail abnormality with cleft palate and/or lip. In our patient, there was an association with bifid uvula that is considered a minor
\end{abstract}

form of palatine fissure. There seems to be an association of congenital curved nail of the fourth toe with cleft palate to different degrees; however, the pathogenesis of the deformity remains unknown.

(c) 2017 S. Karger AG, Basel

\section{Introduction}

Congenital curved nail of the fourth toe (CNFT) was first described by Iwasawa et al. [1] in 1991 and represents an unusual deformity in which the nail covers not only the dorsal but also part of the plantar area of the distal phalanx $[1,2]$.

\section{KARGER}

(C) 2017 S. Karger AG, Basel
Leandro Noriega

Dermatology Clinic

Hospital do Servidor Público Municipal de São Paulo

60 Castro Alves, 5th floor, São Paulo, SP 01532000 (Brazil)

E-Mail leandronorieg@gmail.com 

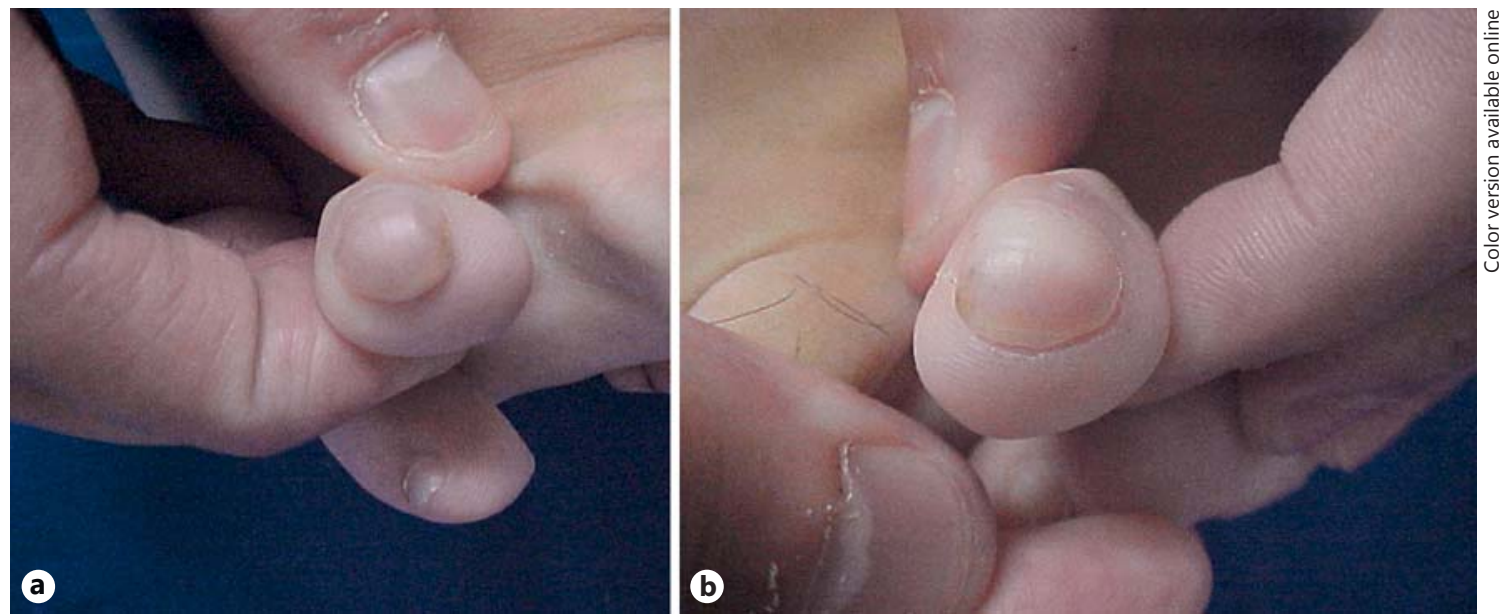

Fig. 1. The nail of the fourth toe curves in a plantar direction. a Right. b Left.

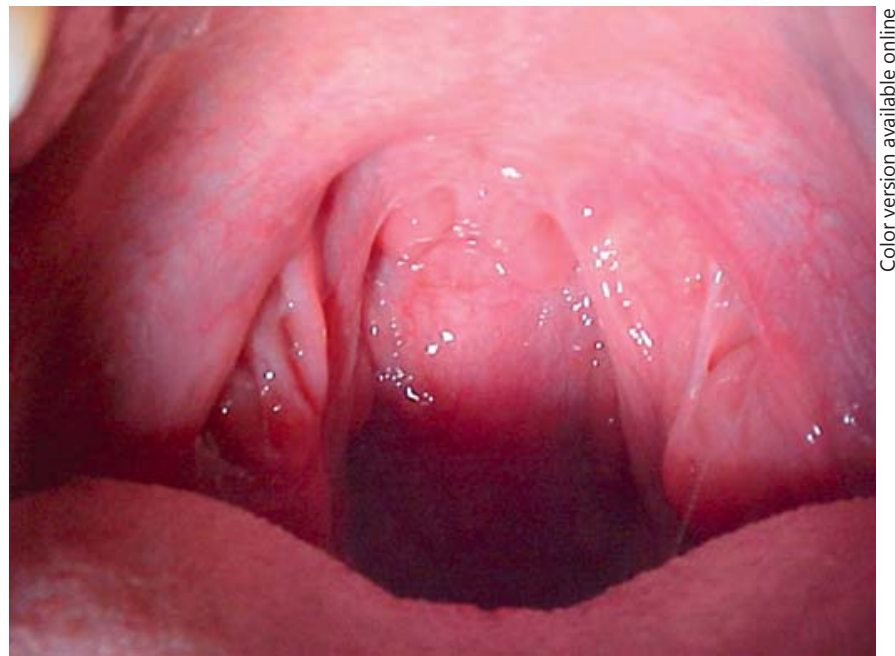

Fig. 2. Bifid uvula.

It is unknown why only the fourth toe is affected, but the initial descriptions suggest that it is a secondary change due to soft tissue and bone abnormality. By some authors, CNFT is considered a mesodermal defect [1, $3-5]$. Currently, it is thought to have an autosomal recessive inheritance, and rare reports associated with other malformations have been published $[2,4,5]$.

Congenital CNFT is usually asymptomatic and bilateral, and the movement of the interphalangeal joints is preserved $[1,4]$. White discoloration of the proximal nails and hyperkeratotic digital plaques may occur [4]. Pterygium inversum unguis, congenital claw-like fingers and

Congenital Curved Nail of the Fourth Toe toes, traumatic hook nail, and parrot beak nail are considered the main differential diagnoses $[2,4]$.

We describe a case of congenital CNFT associated with bifid uvula.

\section{Case Report}

A 21-year-old Caucasian male presented with a nail abnormality since birth, without symptoms. He denied a history of gestational complications and previous local traumas. The dermatologic exam showed nail plates curved from the dorsal toward the plantar area of the distal phalanx of both fourth toes (Fig. 1). Bifid uvula was observed at oroscopy exam (Fig. 2), and an X-ray of the fourth toes showed bony hypoplasia of the distal phalanges (Fig. 3). Family history revealed that his deceased grandfather had a similar nail abnormality, without other anomalies.

\section{Discussion}

Congenital CNFT is a rare nail disorder, and there have been 23 cases in 7 reports only, all from Asian countries [1-8]. Previously reported cases in the literature showed that males are more commonly affected, with an approximate prevalence rate of $78 \%$, and that $86.9 \%$ present with bilateral affection, as in our case [1-8].

The most common radiographic alteration is bone and soft tissue hypoplasia of the distal toe area; however, lack of the crescent-shaped cap of the distal phalanx or distal symphalangism may occur $[1,2,4,5]$. Usually, the lengths of the metatarsals are normal [5]. Our case showed bone hypoplasia of the distal phalanges in the affected toes. 
Fig. 3. Radiologic examination: bony hypoplasia of the distal phalanx of the fourth toe.

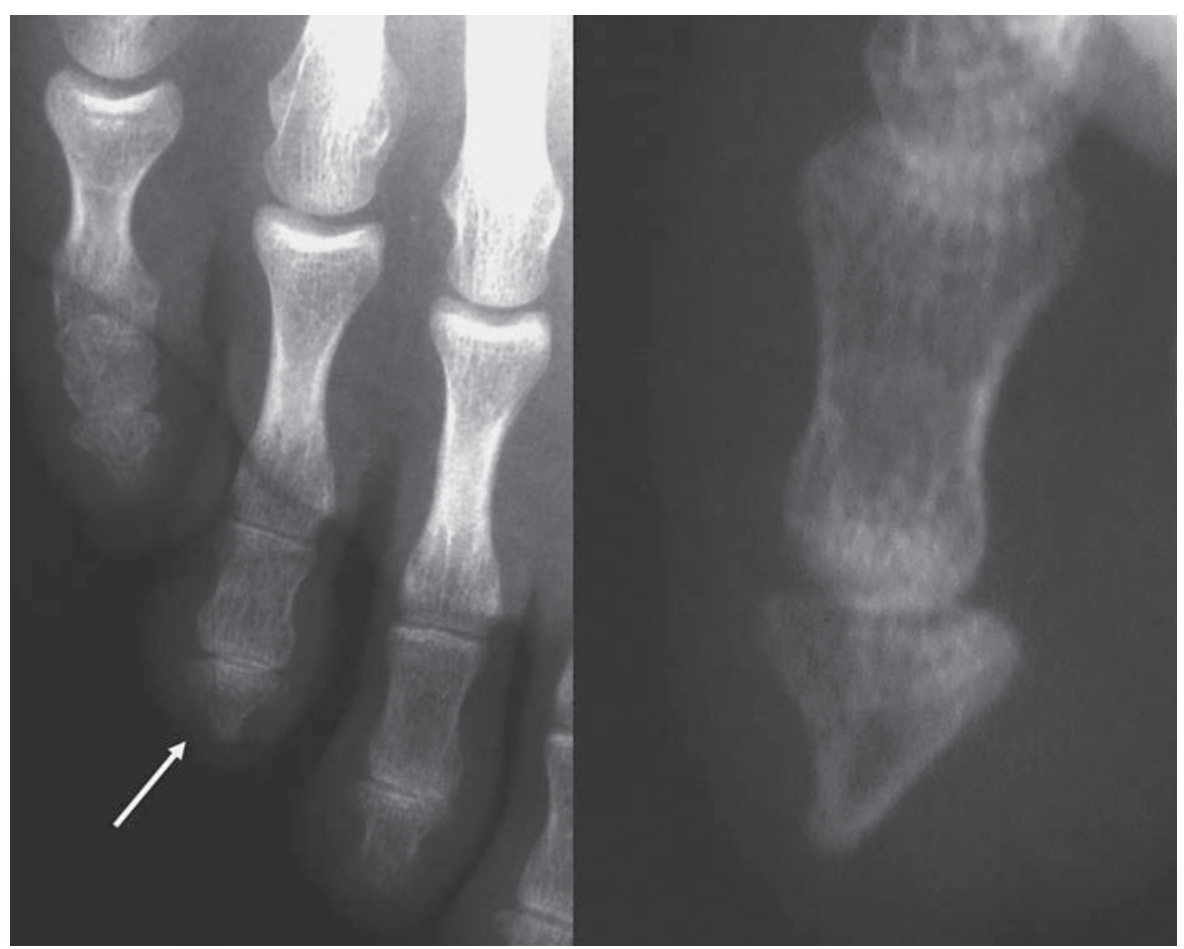

This deformity is rarely associated with other digital anomalies, among which we could cite thumb polydactyly [1], congenital malalignment of the contralateral fourth toenail [3], and very slight curvature of the nail plates of the other toes [5]. As for other abnormalities, there are only 2 reports mentioning the association of congenital CNFT with cleft palate and/or lip $[1,5]$. In our patient, there was an association with bifid uvula that is considered a minor form of palatine fissure in which incomplete merging of the palate processes is observed [9]. Because the uvula is posterior to the incisive foramen, it is formed by the secondary palate. This embryological structure begins at 8-9 weeks of gestation, and its development may be influenced by genetic and environmental factors [10].

The initial development of the nail unit occurs at 6-18 weeks of pregnancy, and the first structures to appear are continuous shallow grooves forming the nail field, which are initially ovoid and later become flat [1, 11]. Subsequently, the globular blebs of periderm cells most often accumulate in the fingertips [11]. Miura [12] described the ungual phalanges as the first skeletal elements to ossify in the embryonic hand, suggesting that the congenital CNFT occurs due to an early pregnancy problem.
Nail changes can be a sign of hereditary or acquired disease. Knowledge of the embryology and anatomy of the nail unit is fundamental for understanding the hereditary nail disorders [13]. A genetic approach may be useful to clarify the cause of this disease, since it is thought to have an autosomal recessive inheritance [1]. There seems to be an association of congenital CNFT with cleft palate to different degrees; however, the pathogenesis of the deformity remains unknown.

\section{Statement of Ethics}

The authors have no ethical conflicts to disclose. The patient's consent has been obtained.

\section{Disclosure Statement}

The authors have no conflicts of interest to declare.
Di Chiacchio/Noriega/Di Chiacchio/ Ocampo-Garza/Padoveze 


\section{References}

1 Iwasawa M, Hirose T, Matsuo K: Congenital curved nail of the fourth toe. Plast Reconstr Surg 1991;87:553-554.

2 Yotsumoto S, Kanzaki T: Curved nail of the fourth toe. J Am Acad Dermatol 1999;40:124125.

3 Choi YH, Song CH, Lee JS, Lee SJ, Kim DW, Lee WJ: Congenital malalignment of the fourth toenail with congenital curved nail of the contralateral fourth toe. Ann Dermatol 2013;25:133-134.

4 Lin YC, Wu YH, Scher RK: Congenital curved nail of the fourth toe - three different clinical presentations. Pediatr Dermatol 2007;24: 380-383.
5 Mitsukawa N, Karube D, Saiga A, Akita S, Kubota Y, Kuriyama M, Satoh K: Surgical treatment for congenital curved nail of the fourth toe. Ann Plast Surg 2015;74:361-364.

6 Higashi N, Kume A, Taniguchi T, et al: Congenital curved nail of the fourth toe. J Pediatr Dermatol 1999;18:153-155.

7 Ito S, Umebayashi Y: Curved nail of the fourth toe. Hifurinsho 2000;42:668-669.

8 Kuramochi M, Hamasaki Y, Hatamochi A, et al: A case of congenital curved nail of the forth toe. Jpn J Clin Dermatol 2009;63:45-47.

9 Iriarte Ortabe JI, Piette E: The presentation of cleft palate in isolation or as part of a syndrome (in Spanish). An Otorrinolaringol Ibero Am 1990;17:405-443.
10 Zajac DJ, Vallino LD: Evaluation and Management of Cleft Lip and Palate: A Developmental Perspective. San Diego, Plural Publishing Inc, 2015, pp 23-48.

11 Mazzarello V, Dessì AL: Ontogenesis of the human fetal nails. I. Observations using the scanning electron microscope (in Italian). Boll Soc Ital Biol Sper 1990;66:441-448.

12 Miura T: Two families with congenital nail anomalies: nail formation in ectopic areas. J Hand Surg Am 1978;3:348-351.

13 Fistarol SK, Itin PH: Nail changes in genodermatoses. Eur J Dermatol 2002;12:119-128. 